\title{
Characterization of the Organic Matter in the Formations with Juniperus phoenicea, and Pinus halepensis in the Matorrals of the Mostaganémois Littoral
}

\author{
N. Lahouel, N. Benabadji, D. Benmansour \\ University Aboubekr Belkaid, Tlemcen, Algeria \\ Email: Lahouel1@yahoo.fr
}

Received 12 February 2014; revised 12 March 2014; accepted 18 March 2014

Copyright (C) 2014 by authors and Scientific Research Publishing Inc.

This work is licensed under the Creative Commons Attribution International License (CC BY). http://creativecommons.org/licenses/by/4.0/

\section{(c) (i) Open Access}

\begin{abstract}
In the present work, we were able to verify the utility of splitting the organic matter that seems to be indispensable, especially when it comes to the soil humus which is very little polymerized and containing a large proportion of non-decomposed organic matter. This study even if it remains unfinished, it provides some useful information. Moreover, this work reflects the fundamental influence exerted by the organic matter as a soil and as a driving force of its dynamics. Humus factor in the vocation of a soil can promote or remove some plant species. The statistic analysis shows that the humification of the organic matter is faster on calcareous sandstone substrate (Calabrien) as on Tithonique Substrate with advanced cretaceous which can be explained by the very high rate of humic acids as the calcareous sandstone substrate. At the level of plant development, the organic matter provided by the mixed stands (Eucalyptus, Pinus halepensis, Juniperus phoenicea) with an undergrowth which is formed by (Retama monosperma, calycotome spinosa, Pistachia lentiscus, Phylaria latifolia, Lavandula stoecka) has a very god humification with a predominance of humic acids that indicate the acceleration of the development of clay-humic complexes and a permanent wealth of energy reserves.
\end{abstract}

\section{Keywords}

Organic Matter, Humus, Soil, Humic Acids, Plant Development, Clay-Humic Complexes, Bourahma Forest, Mostaganem, Algeria 


\section{Introduction}

The forest environment is a net sample of ecosystem organized by superimposed layers; this allows the maximum use of solar energy as well as a greater diversification of the ecological niches [1].

Among the essential components in this environment, there is the organic matter which plays a key role here. It constitutes the essential substrate of the development of the biological life because it is a major source of carbon and energy for the microorganisms. It determines the chemical properties (carbon, nitrogen and phosphorus stocks) and the physical properties (permeability, structural stability, retention and water circulation and capacities) of soil [2]-[4].

The soils are specific environment which allow the plan life but each living species has its requirements for mineral organic substances and for water, and it takes up a limited part of soil specific nature [5].

Thus, we focus our work especially on the soil and the organic element. These latters are responsible for the decay of Juniperus phoenicea stands. The organic matter both in quantity and inquality cannot be proactive by the root system of this forest gasoline. Sometimes, these nutritional difficulties (absorption) can lead to damaging results in terms of features (stunting, limited growth...). The results are noted for decay of stands that this work intends to investigate. We were interested in characterization of the organic matter of the Mostaganem coastline. It is the question of Bourahma forest.

As interested in the forest subjects faced with the scale of this evident degradation, we thought it useful to do this study. In this context, we suggest that we can provide a contribution on the question of relationships between soil and vegetation in the forest area. It will be very informative.

In another chapter, we will make the analysis of edaphic data received by the statistical processing. It is the Principal Component Analysis (PCA). This desired approach in this kind of study will allow us to identify the correlations which can exist between these multi-specific, monospecific groupings and the dominant ecological factors related to the soil (texture, $\mathrm{pH}$, organic matter...).

\section{Approach Methodology}

\subsection{Field Methodology Figure 1}

\subsubsection{Soil Sampling}

The different methods of study and characterization of soils that have been proposed all lead to the sampling of topsoil [6]. However, the soil sampling does not only consist in taking off a certain quantity of the soil and in analyzing at the laboratory. It must respond to a need related to the context of the site and its occupation [7].

\subsubsection{Sampling Strategies in Pedology}

There are many methods and standards of soil sampling and analysis that can be adapted for soil study:

- The random method.

- The stratified random method.

- The systematic method.

- The systematic random method.

- The systematic semi-random method.

- The incomplete systematic stratified method.

In our case, the stratified random method of the area is better, because it requires to make a large number of samples where the choice of their locations is based on determining factor. Our choice is based on the geological substrate and the plant development which identify the type of the organic matter and the state of its development.

Many factors can be taken into consideration for the realization of this process such as the geological substrate, the lithosoils, the geomorphology, the soil and plants occupation [8].

The sampling strategy to set up in order to proceed on the investigation of the soil is much more led by the nature of required information [7].

\subsection{Laboratory Methodology}

\subsubsection{Extraction and Fractionation of Humic Matters of the Soil}

Description of the technique In order to ensure truly reproducible results, it is essential to standardize as far as 
The area of study: forest ecosystem of the Mostaganémois littoral

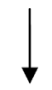

The ecological zone: Drill of Bourahma

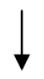

Choice of the sampling procedure

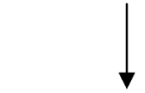

The site of the points of survey.

The realization of the device of sampling.

Qualitative data

- collection of data concerning the ground

- execution of the pedological statements

- collection of data concerning

vegetable associations ground
Quantitative information

- Physicochemical and biochemical

Analyses of the samples taken

- Statistical analysis of the data.

Figure 1. Experimental methodological approach.

possible the extraction method. The soil is crushed and sieved through the riddle $0.2 \mathrm{~mm}$. the relationship soil/ reagent is 5/100 for each sample, but in the case of the poor soil, it is often necessary to take 20/100.

- Shake for half $1 \frac{1}{2}$ an hour $10 \mathrm{gr}$ of soil in $200 \mathrm{ml}$ of $\mathrm{PO}_{4} \mathrm{H}_{3}$ (136 ml per liter of water). Repeat the process two times.

- The light plant matters are collected on filter and dried. Carbon analysis is done by combustion.

- The phosphoric solution containing free fulvic acids is preserved.

- The soil base is washed with water to a pH of 4.5 to 5. After washing, the soil is shaken for 4 hours with 200 $\mathrm{ml}$ of $\mathrm{Na}_{4} \mathrm{P}_{2} \mathrm{O}_{7} .0,1 \mathrm{M}$.

- The extraction liquid is centrifuged and settled on filter.

- The soil residue is shaken for 4 hours with $200 \mathrm{ml}$ de $\mathrm{NaOH} 0.1 \mathrm{M}$, centrifuged and settled on filter. The process is repeated two times. The filtrates corresponding to the pyrophosphate extraction and soda are pre- 
served separately.

- The aliquot of each solution is dried in oven and the carbon is determined either by the potassium dichromate, or combustion and determining of released $\mathrm{CO}_{2}$. This determines the whole humic matters (fulvic acids + humic acids) [9].

- On an another aliquot, the humic acids are precipitated by $\mathrm{H}_{2} \mathrm{SO}_{4}$ with $\mathrm{pH} 1$, the precipitate is washed and the carbon is determined as before (humic acids).

- The fulvic acids are obtained by difference: $\% \mathrm{C}$ fulvic acids $=\% \mathrm{C}$ whole humic matters $-\% \mathrm{C}$ humic acids.

- The free fulvic acids are directly determined by the sulphochromic oxidation of the phosphoric extract.

- The soil residue after the second soda extraction is dried, and the whole residual carbon is determined. Thus, we get the insoluble or humin fraction.

- In the end, there are seven different fractions of organic matters:

$+\mathrm{C} \%$ of the light plant matters.

$+\mathrm{C} \%$ of the fulvic acids extracted from sodium pyrophosphate.

$+\mathrm{C} \%$ of the humic acids extracted from sodium pyrophosphate.

$+\mathrm{C} \%$ of the fulvic acids extracted from soda.

$+\mathrm{C} \%$ of the humic acids extracted from soda.

$+\mathrm{C} \%$ Humin.

$=\mathrm{C} \%$ total $[10]$.

Geographical location of the study area is mentioned in the Figure 2.

\section{Results and Discussion}

\subsection{Variability of the Analyzed Parameters According to Plant Association and Geological Substrate}

\subsubsection{Variability of the Rate of (OM) According to the Undergrowth}

Figure 3 represents the rate variation of the organic matter in order of horizon groups and plant association (undergrowth), it is noticeable that the association (C) (Phylleria latifolia, Pistachia lentiscus and Lavandula stoecka) gathers a large number of horizon groups together with a very high rate of organic matter, and next we have the association (B) (Retama monosperma, calycotom spinosa and Pistachia lentiscus) and (E) (Pistachia lentiscus and Disse), and then come the other associations represented by a smaller number of horizon groups and the average rates of the oraganic matter.

\subsubsection{Variability of the Rate (OM) According to Forest Groups}

Figure 4 represents the rate variation of the organic matter in order of horizon groups and plant groupings (forest group), it is noticeable that the group (D) (Pinus halepensis) gathers a large number of horizon groups together with a very high rate of organic matter, and next we have the grouping (E) (Pinus halepensis and Juniperus phoenicea) and then come the other groupings (A) (Eucalyptus, Juniperus phoenicea and Pinus halepensis) and (C) (Pinus canariensis and Pinus halepensis) by a smaller number of horizon groups and the average rates of the oraganic matter.

\subsubsection{Variability of the Fulvic Acids Rate According to the Forest Groups}

Figure 5 represents the rate variation of the fulvic acids in order of horizon groups and plant groupings (forest group), it is noticeable that this rate is very high in the grouping (E) (Pinus halepensis and Juniperus phoenicea) with a small variation going from the horizon (1) to the horizon (2) and (3), and it has average values in the groupings (A) (Eucalyptus Juniperus phoenicea and Pinus halepensis) and (B) (Eucalyptus, Juniperus phoenicea and Pinus halepensis) with a remarkable difference between the surface horizon (1) and the two other horizons (2) and (3) whereas these values are very small variation between the three horizons.

\subsubsection{Variability of the Humic Acids Rate According to the Forest Groups}

Figure 6 represents the rate variation of the humic acids in order of horizon groups and plant groupings (forest group), it is noticeable that this rate is very high in the grouping (B) (Eucalyptus, Pinus halepensis and Juniperus phoenicea) with a notable decay from the horizon (1) to the horizon (3), whereas this rate is on average in the other groupings with a verya small variation between the three horizons. 


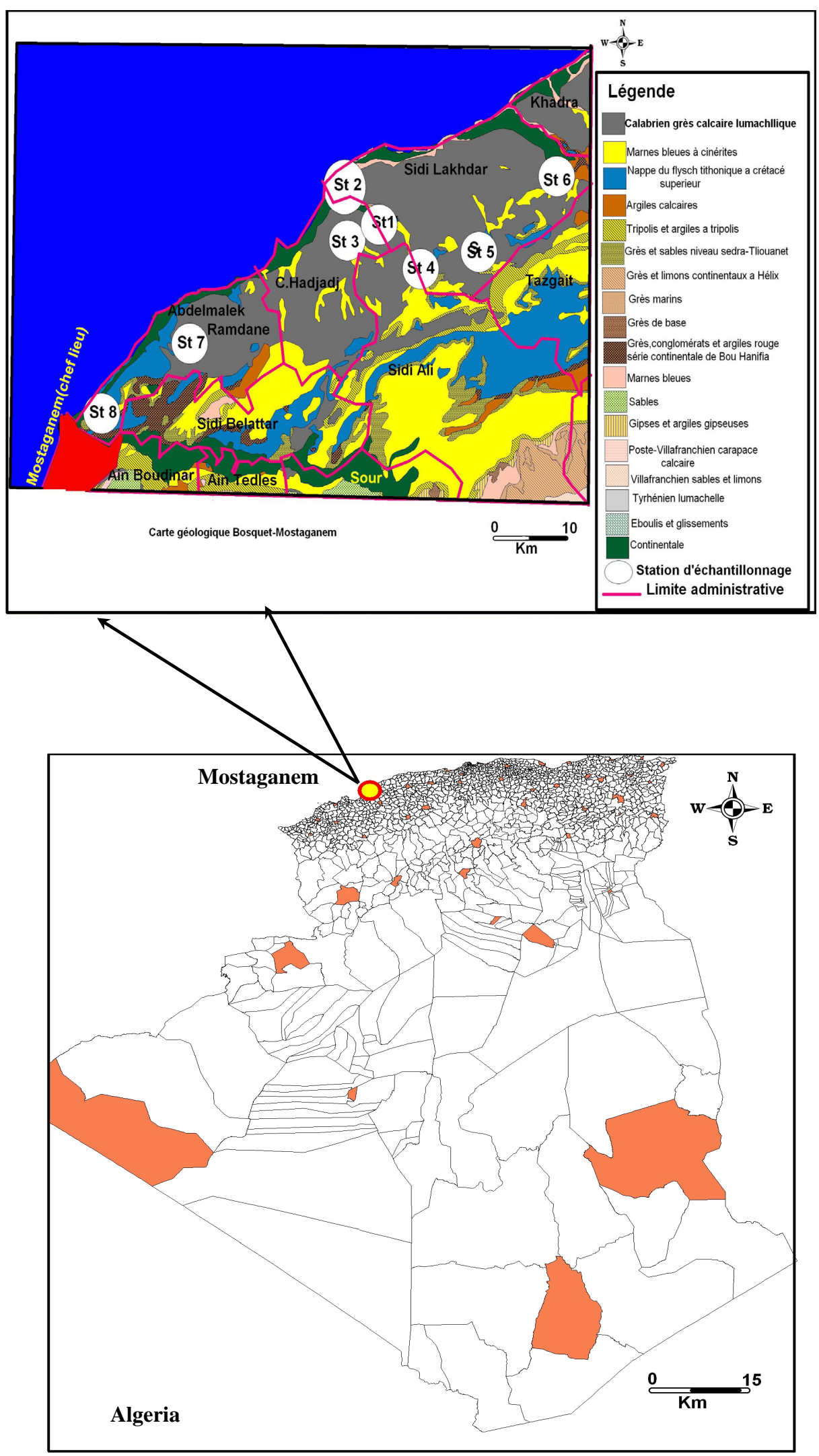

Figure 2. Geographical location of the study area. 


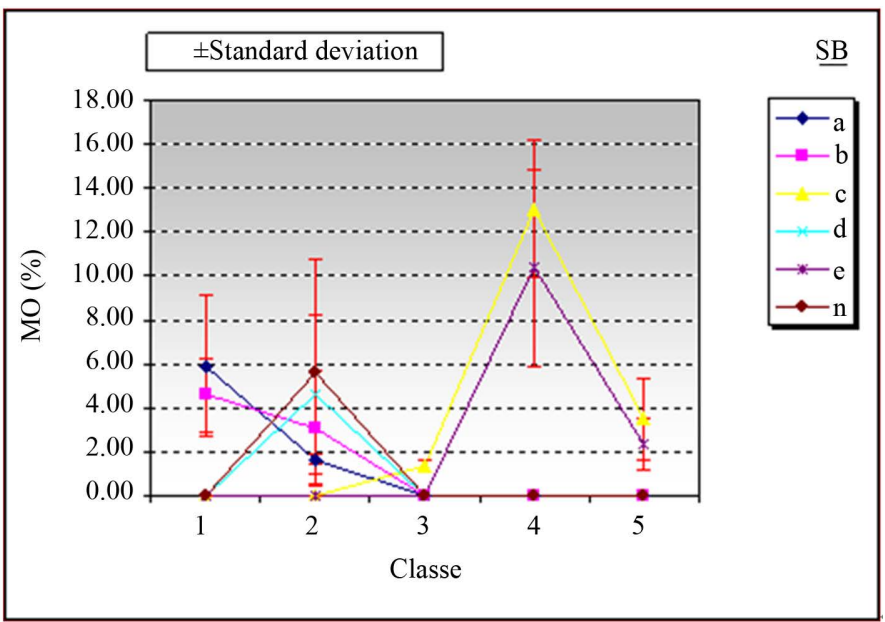

Figure 3. Chart of the variability of the rate of the organic matter by association plant (under wood).

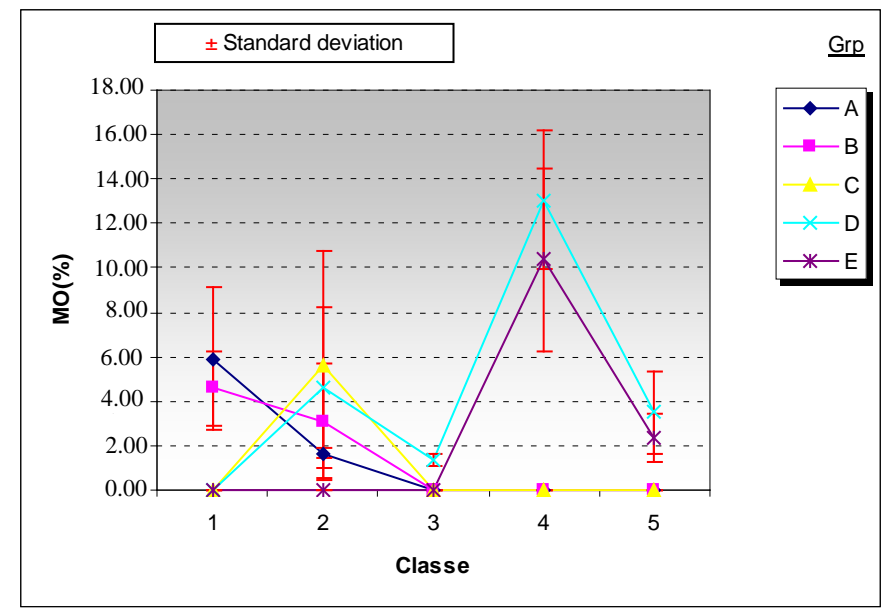

Figure 4. Chart of the variability of the rate of the organic matter by forestry groups.

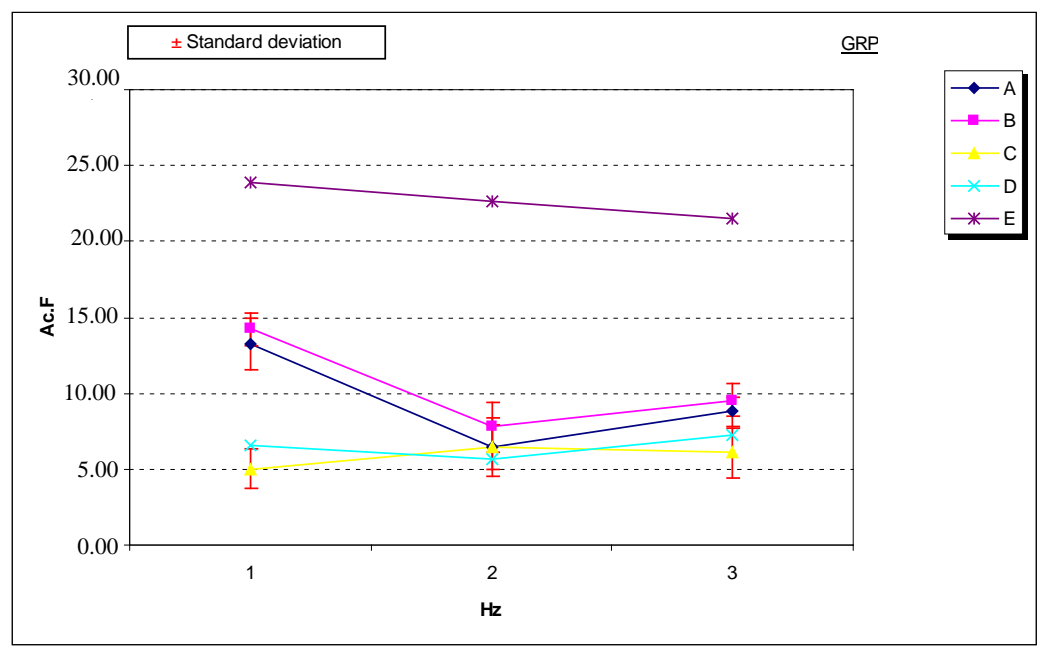

Figure 5. Chart of the variability of the rate of the fulvic acids by forestry groups. 


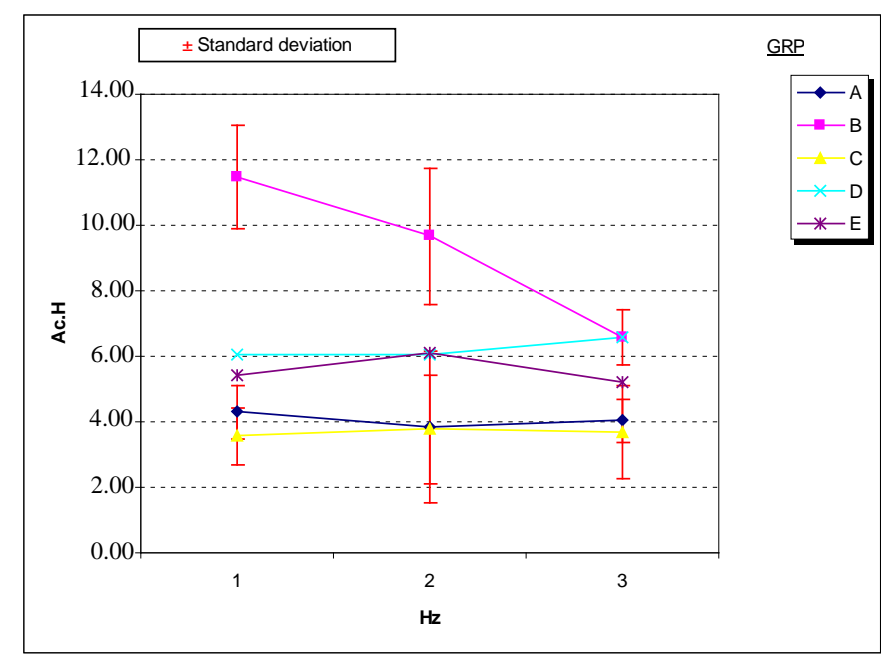

Figure 6. Chart of the variability of the rate of the humic acids by forestry groups.

\subsubsection{Variability of the Fulvic Acids Rate According to the Undergrowth}

Figure 7 represents the rate variation of the fulvic acids in order of horizon groups and plant association (undergrowth), it is noticeable that this rate is very high in the association (E) (Pistachia lentiscus and Disse) with a small variation going from the horizon (1) to the horizon (2) and (3), and it is on average in the association (A) (Lavandula stoecka, Pistachia lentiscus and Retama monosperma) (B) (Retama monosperma, Calycotom spinosa and Pistachia lentiscus) and (D) (Pistachia lentiscus) with a remarkable difference between the surface horizon (1) and the two other horizons (2) and (3) in the association (A) and (B) and it is non-existent in the association (D) whereas these values are very small in the associations (C) ( Phylleria latifolia, Pistachia lentiscus and Lavandula stoecka) with a very small variation between the three horizons.

\subsubsection{Variability of the Humic Acids Rate According to the Forest Groups}

Figure 8 represents the rate variation of the humic acids in order of horizon groups and plant association (undergrowth), it is noticeable that this rate is very high in the association (B) (Retama monosperma, Calycotom spinosa and Pistachia lentiscus) with a remarkable decline from the horizon (1) to the horizon (3) and it is on average in the other associations with a small difference between the three horizons.

\section{Conclusions}

In the ecosystems both climatic and altered by humans, the humification is a controller process: the energy content is maintained, the complexity level is high, the homeostasis of the system is assured, its organization is increased but its entropy reduced. The crop rotation, the mixed stands, the plants development climax balanced with the natural environment are examples where the humus, by way of feedback or directly, take part in the system regulation by a biological and chemical diversification.

However, each simplification tends to lead to change, an accelerated evolution in the direction of instability, of mineralization of the energy reserves that increases the system entropy by decreasing the quantity and by altering the humus quality. The monocultures illustrate this orientation.

We have completed this work which consists in characterize the organic matter in a forest ecosystem of the coastal region of Mostaganem. This work is informative and useful especially in the timber production.

The specific knowledge of the principal plant development, the lithological substrate and the physicochemical aspects of soil as well as the bioclimatic characterization constitute the fundamental bases to better understand the evolution of the humic compounds in the ecosystem.

According to some authors [11], the fulvic acids being the first humic fractions which are formed in the soil during the decomposition of the fresh organic matter, are either quickly transformed into humic acids (by polymerization and neosynthesis) or quickly decomposed and mineralized. These two phenomena can leave a small proportion of humic acids highly polymerized. 


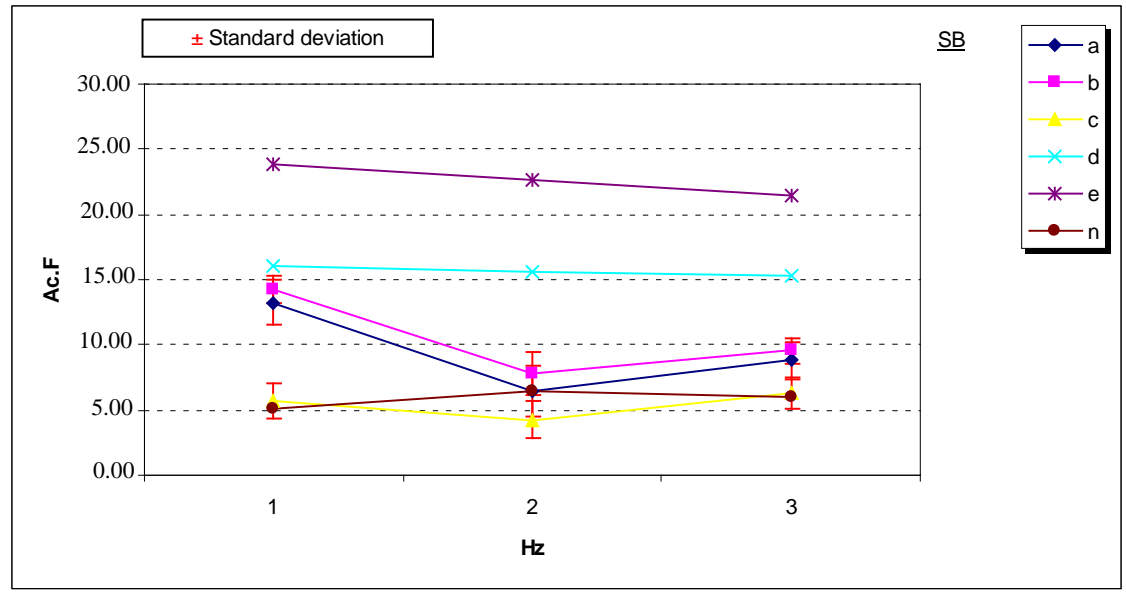

Figure 7. Chart of the variability of the rate of the fulvic acids by association plant (under wood).

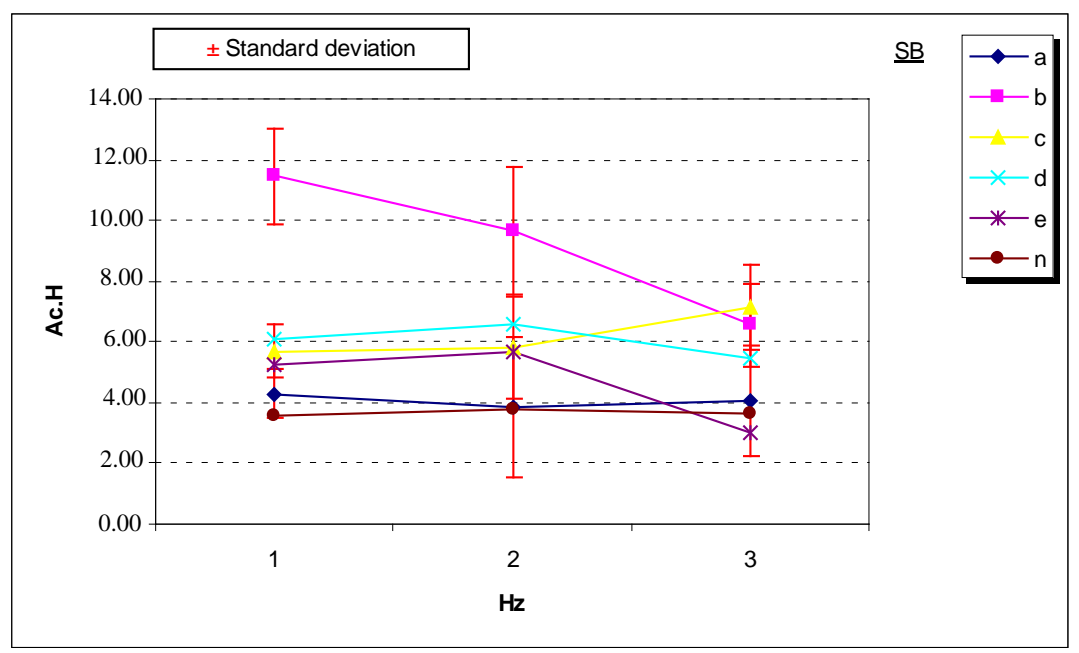

Figure 8. Chart of the variability of the rate of the humic acids by association plant (under wood).

The fractionation of the fresh organic matter and the dosage of these different humic compounds (fulvic acids and humic acids) allow us to better know the development state of the organic matter.

Through a statistical analysis in order to study the variability of these humic compounds according to different plant development, it has been noted that the organic matter provided by the mixed stands (Eucalyptus + Juniperus phoenicea + Pinus halepensis) with an undergrowth made of: (Retama monosperma + Calycotome spinosa + Pistachia lentiscus + Phyllereo latifolia + Lavandula stoecka), represents a very good humification with a predominance of the humic acids which indicates the acceleration of the development of clay-humic compounds and a permanent wealth of the energy reserves.

The responsible decision-makers for the forestry promotion and the environmental protection must take account of the speed of the degradation of these forest ecosystems and of the soil quality in the long term in the region. To achieve this, they are obliged to intervene by:

- The preservation of forest groups which constitute the plant structures relatively stable with plant association of characteristic and significant species.

- The restoration of pre-forest groups, by far, the most frequent, represents structures, usually in the form of tree-filled matorrals, blocked under the current ecological conditions and the anthropogenic activities which are still present. 


\section{References}

[1] Dajoz, R. (1985) Precis of Ecology. ED. Bordered, Paris. 505p.

[2] Fustec-Mathon, E., Righi, D. and Jambu, P. (1975) Influence of the Bitumens Extracted from Podzols Humic Hydromorphic of the Moors of the Medoc on the Telluric Microflora. Rev. Ecol. Biol. Ground., 12, 393-404.

[3] Jambu, P., Amblès, A., Jaquesy, J.C., Secouet, B. and Parlanti, E. (1983) Incorporation of Natural Alcohols from Seedling Residues into Has Hydromorphic Forest-Podzol. Newspaper of Soil Science, 44, 135-146. http://dx.doi.org/10.1111/j.1365-2389.1993.tb00440.x

[4] Dutartre, P., Bartoli, F., Andreux, F. and Portal, J.M. (1993) of Influence Content and Nature of Organic to Subdue One the Structure of Sum Sandy Soils from West Try in Density Fractions of Oxisol under Forest and Pasture. Australian Journal of Soil Research, 33, 59-76.

[5] Becker, Mr. (1971) Study of the Relations Ground-Vegetation in Conditions of Hydromorphy in a Forest of the Lorraine Plain. Thesis Doctorate of State, Univ.Nancy, 225 pages.

[6] Marc, P., et al. (1998) Observation on the Grounds and of the Grounds Mediterranean: Cover over with Soil and Grounds in Twyers-Side, 146p.

[7] Laperche, V. and Mossman, J.R. (2004) Protocol of Sampling of the Urban Grounds Polluted by Lead. RP-52928-FR, Doc. pdf.

[8] Baise, D. and Jabiol, B. (1995) Guide for the Description of the Grounds. Edition I.N.R.A, Paris, 375p.

[9] Duchaufour, P.H. and Jacquin, F. (1963) Search for a Method of Extraction and Fractionation of the Humic Compounds Controlled by the Electrophoresis. Annals Agronomic.

[10] Faure, J. and Picat, P. (1973) On the Distinction between Humic and Acid Acids Fulvic. Bull of Ace france Science of ground N., 2, 91-95.

[11] Nkundikije-Desseaux, V., Halitim, A., Galben, T. and Ygnatov, Mr. (1976) Test of Characterization of the Organic Matter in Some Grounds of the North of Algeria, 60p. 